\title{
Managing Global Experiences for Engineering Students
}

Session 2560

\author{
Natalie A. Mello \\ Worcester Polytechnic Institute
}

\begin{abstract}
Worcester Polytechnic Institute (WPI) has long embraced a project-based curriculum that now extends to the four corners of the globe. With established programs in Europe, the Far East, Latin America, Australia, the US and new initiatives in Hong Kong and Taiwan, WPI provides opportunities for undergraduates to complete meaningful off-campus experiences. WPI offers students the freedom to complete degree requirements away from campus in a professional experience under the direct supervision of WPI faculty, an experience that is unrivaled by traditional international study abroad. The impact of successfully completing professional-level projects at remote locations is that students solve real-world problems while immersed in a different culture. In 1999-2000, more than 400 of WPI's typical graduating class of 650 students completed one or both qualifying projects in teams off campus on externally sponsored topics. In the 2000-01 academic year, WPI is sending over 450 students to one of WPI's off-campus residential Project Centers. WPI's program is not a traditional study-abroad program. This paper will provide an understanding of the management and logistical structure of Global Perspective Program at WPI, with special attention paid to risk management issues, student and faculty recruiting and preparation, and re-entry for returning students.
\end{abstract}

\section{Introduction}

There has been an increase in the call for internationalizing higher education by representatives of government, academia and industry. President Clinton's recent memorandum to the heads of executive departments and agencies regarding the International Education Policy states:

To continue to compete successfully in the global economy and to maintain our role as world leader, the United States needs to ensure that its citizens develop a broad understanding of the world, proficiency in other languages, and knowledge of other cultures... It is the policy of the Federal Government to support international education. We are committed to:

- Promoting study abroad by U.S. students...

- Expanding high-quality foreign language learning and in-depth knowledge of other cultures by Americans...

Engineering education has long been faced with the challenge of providing a global perspective for its undergraduates. The ASEE's report, Engineering Education for a Changing World,

Proceedings of the 2001 American Society for Engineering Education Annual Conference \& Exposition Copyright 2001, American Society for Engineering Education 
presents a typical viewpoint:

[E]ngineering colleges must not only provide their graduates with intellectual development and superb technical capabilities, but, following industry's lead, [they] must educate their students to work as part of teams, communicate well, and understand the economic, social, environmental, and international context of their professional activities. $^{2}$

WPI recognized over 25 years ago that the practice of engineering, science and management is best learned by a student through a process of 'initiation into a tradition' as an apprentice to a master ${ }^{3}$. Such an approach to engineering education has been enhanced by the addition of several project centers located around the world. WPI's focus on learning by experience is shared as well by many current educational theorists and practitioners, supported by leading work in the cognitive sciences ${ }^{4-8}$. Researchers in these fields increasingly recognize that, in order for students to become full members of a 'community of practice,' it is essential that they have opportunities for 'legitimate participation' ${ }^{4}$ in the practices of that community. WPI's Global Perspective Program has exploited the converging interests of the federal government, cognitive science, and engineering education.

However, as WPI students increasingly take advantage of the opportunities that WPI offers to complete academic work off campus, the likelihood of a serious incident occurring off campus increases as well. One need only read the popular press to become nervous about sending students to all parts of the globe. Current national opinion is that universities owe their students more attention to risk management and care when students travel as part of their academic experience. ${ }^{9}$ With the recent unfortunate tragedies that have occurred in Costa Rica, India, Guatemala and Japan involving students on some form of "study abroad", more attention is being paid to how these experiences are managed by the institutions. ${ }^{10-14}$

\section{WPI's Global Perspective Program}

In 1970, WPI adopted a new curriculum, called the WPI Plan. The WPI Plan replaced a traditional, course-based technical curriculum with a project-based program emphasizing teamwork, communication, and the integration of technical and societal concerns. Among the degree requirements of this program are three substantive projects: one in the humanities and arts, one in the student's major area of study, and one that explores the interrelationship between society and technology. WPI's off-campus opportunities take the form of one of these three projects. $^{15,16}$

In 1976, the first WPI residential Project Center was established in Washington, DC. The Project Center model involves groups of students working off-campus full-time on degreerequired projects. The students are accompanied by WPI faculty advisors, and develop solutions to problems proposed by agencies and organizations at the site. Since that time, this program has expanded to include operations in London, Venice, Bangkok, Boston, San Juan (Puerto Rico), San José (Costa Rica), Zurich, Melbourne, Limerick and Copenhagen; current exploratory sites

Proceedings of the 2001 American Society for Engineering Education Annual Conference \& Exposition Copyright 2001, American Society for Engineering Education 
include new programs in Hong Kong and Taipei. These centers serve as real-world laboratories in which students focus on the solution of projects. This is not a traditional study-abroad program. This is what is known as the Global Perspective Program at WPI.

\section{Project Center Personnel}

In order to understand how WPI manages the risk associated with the Global Perspective Program, it is important to understand the context. WPI has several levels of participation in the project centers that contribute to its success. Each center has a full time faculty member associated with it referred to as a Center Director. This Center Director oversees the pedagogical concerns associated with projects, selects the student participants for their site and works with the Local Coordinator. The Local Coordinator is a resident of the site who maintains contact with project sponsors, helps to arrange housing and serves as a resident expert for the students and faculty when they are on site. There are full-time WPI faculty members who go with the students for the duration of the project experience who are referred to as the Resident Faculty Advisors. These Advisors prepare with the students for the term before they depart for the site, live on site with the students and advise the projects.

In addition to the roles described above, the Interdisciplinary and Global Studies Division (IGSD) through which these residential project experiences are administered also employs administrators. The leadership team for this Division is comprised of four individuals who separately oversee different components of the off-campus experience and who together decide policy and procedures that affect all participants - students, Resident Faculty Advisors, Center Directors and Local Coordinators. There are also several support staff members who facilitate all of the details involved in administering such a large program.

The Global Perspective Program at WPI has experienced tremendous growth in the past four years. As the numbers of students going off campus began to increase, it became obvious that the IGSD could not work in a vacuum to address issues of risk management. It only took one perceived crisis in the making to bring the right players together to form the team that deals with the risks associated with sending students off-campus. This team is comprised of the Director of Global Operations in the Interdisciplinary and Global Studies Division, the Associate Treasurer for the University and an insurance and liability consultant hired by the university.

\section{Risk Management Defined}

Part of the process of working towards managing the risks WPI saw itself being exposed to was defining what "risk management" means to the institution. The risk management team, described previously, identifies various exposures, and measures these exposures against WPI's willingness and ability to withstand potential losses resulting from these exposures. The team determines how to implement policies to best control these identified risks with appropriate procedures. These policies and procedures are reviewed each year and are specific to each site.

Proceedings of the 2001 American Society for Engineering Education Annual Conference \& Exposition Copyright 2001, American Society for Engineering Education 
WPI believes that effective risk management is a combination of two methodologies. The first is a philosophical approach that aims to identify, analyze, and manage risks. The second must be a practical approach that is tailored to each site. The ultimate goal of this combination is to protect the students, the advisors, the program and the institution.

\section{Risk Management Resources}

There are two major resources that have been developed by WPI in the effort to protect the students, the advisors, the program and the institution. The first is intended for student use, the second was designed for use by the faculty advisors at a site. Both resources have been in existence for three years, and have grown substantially with time. These resources actually began as handouts that were given to participants. As the piles of information grew and the possibility for overlooking something became evident, the decision was made to bind these handouts together with an explanation of what they were. It also was determined that this would be excellent information to share with participants' families, rather than relying on students to pass on what they thought they understood. These two packets of information have evolved into critical documents that are carefully written and updated every time students travel to an offcampus site - in some cases three times a year to the same site.

The "Going Global at WPI Handbook," intended for students and their families, includes descriptions of all institutional policies, all paperwork that students are expected to complete, and site specific information from reliable sources. This handbook is sent to families with a cover letter, and is given to all students at orientation. IGSD professional staff prepares the handbook with input from Center Directors and Local Coordinators for site-specific information. Included are the NAFSA Health and Safety Guidelines ${ }^{17}$ that have been adopted as the national standard minimal guidelines for institutions sending students off-campus. Resources from governmental agencies that are provided in the handbook include all updated information from the Center for Disease Control and fact sheets from US State Department specific to where the students are going.

Travel information that is provided includes how to get a passport and what needs to be considered regarding visas. The handbook provides information regarding safety when traveling, how to take money and how to safeguard important documents. Each handbook contains contact information for the nearest US embassy or consulate. Important information regarding drugs and the legal system and how it may differ from here in the US is also given.

Medical considerations that students must know include information about how to carry prescription medication and the addresses, phone numbers and directions to nearest, best medical, dental, and mental health facilities. With the help of Local Coordinators, local emergency phone numbers with explicit instructions as to what to say in the local language in case of an emergency are provided. In this handbook we also list the local phone numbers for the Local Coordinator, the Resident Faculty Advisor, and any other important contact information. Maps of the area are also included in the handbook.

Proceedings of the 2001 American Society for Engineering Education Annual Conference \& Exposition Copyright 2001, American Society for Engineering Education 
The "Going Global at WPI Operational Handbook" is a resource that is provided to all Resident Faculty Advisors who are on-site with the students. In addition to all of the information described above included in the students' handbook, the faculty are provided with more information that they may need while in residence. Included is the Crisis Management Plan that contains a detailed description of what to do and who to contact in the event of an emergency. Emergencies that are anticipated include such things as natural disasters, crimes that may be committed against a student, crimes that may be committed by a student, a student's disappearance, sexual harassment, and violations of the WPI's Code of Conduct. Faculty advisors are provided with an extensive list of names and contact numbers for the Crisis Management Team on campus.

\section{Faculty recruitment and training}

Each year, faculty members are chosen from across the campus to participate as residential project advisors at the sites. These advisors travel with the students and reside on site during the entire experience. Responsibilities of the advisors include not only the typical academic issues that arise, but also issues that arise due to living on site and off-campus.

The role of advisor is critical to the success of the educational enrichment that WPI's students experience in their project work. Advisors are responsible to give continuous guidance and mentoring to all of the student teams, sometimes in areas outside of their fields of expertise. Because there are special issues that arise from being away from campus for all participants students and faculty alike - training has been developed specifically for advisors at off-campus locations. A conscientious approach to risk management has necessitated preparing advisors for worst-case scenarios, while also providing the less experienced off-campus advisors with an opportunity to learn from their colleagues who have been away often. Areas of concern that are addressed during these training sessions include: sexual harassment, transportation, alcohol, recognizing and responding to students at risk, health and safety issues, housing concerns, students' behavior, social and personal growth, and helping students get the most of the cultural experience. All of these areas are deemed to be out of the purview of regular project advising and therefore get special attention. Professionals who offer services addressing these issues on campus are brought into the training sessions to offer expert advice about how to deal with the issues off-campus. This training goes beyond that information provided in the "Going Global at WPI Operational Handbook".

To date approximately $25 \%$ of the more than 200 tenured and tenure-track faculty have participated in the Global Perspective Program. The development of faculty expertise and interest in these off-campus interdisciplinary projects is central to the program's success. To insure participation of faculty with the appropriate expertise, a Faculty Development program was initiated in 1997 to facilitate this effort. Faculty may apply for small grants to develop expertise and experience in areas of interdisciplinary studies, and to gain experience in the appropriate foreign language and culture. ${ }^{15}$

Proceedings of the 2001 American Society for Engineering Education Annual Conference \& Exposition Copyright 2001, American Society for Engineering Education 


\section{Student Recruitment}

Typically WPI recruits student participants for the off-campus project centers a full academic year in advance. The recruitment effort begins with a "Global Opportunities Fair" hosted by the IGSD early in the fall. At this Fair, past student participants, Resident Faculty Advisors, Center Directors, and when possible, Local Coordinators are present to share their experiences with potential students. Other critical offices on campus staff booths as well to answer questions regarding financial aid, academic advising, and any other issues that students may have concerns about. Applications with all the information necessary about how to complete the application process are handed out as well. As evidence of the University's strong commitment to international education, every WPI student who obtains a US passport is reimbursed for his or her expense. So in addition to the WPI services provided, a local vendor is present to take free passport photos of every student. Passport applications are available at the Fair as well as a handout describing the procedure to get reimbursed for their US passport.

Students who wish to complete a project off campus must complete a multi-step application process. They submit a written application that includes a biographical essay. All transcripts and judicial records are reviewed as students must be in good academic and judicial standing at the time of application. This is an important screening that begins early in the process so that students who are not eligible are notified immediately. Students attend site-specific information sessions to gather current and factual information about each site. Center Directors interview each student who applies to their site as a first choice. Center Directors review student applications including the standard interviewer guide that is filled out for each applicant. Center Directors select the student participants for the coming year. As students are notified of their acceptance, they are asked to secure their place in the program with a deposit that will go toward their housing costs while off-campus.

\section{IIX. Student Preparation}

Each student, before they leave campus, is prepared in a variety of ways to deal with the experience ahead of them. Completion of preparation activity specific to each project is required for every student participant. In most cases the equivalent of a course and a half of activity is required before a student team is allowed to proceed with their project off-campus.

Each project, regardless of its area of focus, calls upon students to develop specific skills. As students work with broad problem statements and develop specific goals for their project, they are actively engaged in open-ended problem solving. Typically project topics are outside the scope of the students' areas of study, and therefore the students must learn how to learn about new subjects. Teamwork skills are honed and practiced throughout the experience as students work together to produce a solution. The formal documentation and presentation skills required to successfully complete an IQP off-campus insure that students master how to communicate in a variety of mediums and for a variety of audiences.

Proceedings of the 2001 American Society for Engineering Education Annual Conference \& Exposition Copyright 2001, American Society for Engineering Education 
In addition to the academic preparation that students participate in, they are also given orientation and preparation for the cultural, religious and ethnic differences they may encounter off-campus. This may include specific language training, depending on the site. Faculty members with expertise in the area provide a general history of the site where the students are going. Students are instructed as to proper dress, proper etiquette, and how to expect the host country nationals to treat them.

Students are also provided with an Orientation session run by the professional staff of the IGSD. The "Going Global Handbook" is given to the students at this session and reviewed. All mandatory paperwork is explained and deadlines are emphasized. Students are told that failure to submit any paperwork by the deadline will prohibit their participation in the program.

The professional staff covers in detail issues of health, safety, medical insurance, alcohol and drug use, WPI policies and how they are enforced while off campus, and also policies that are specific to the program that the students are preparing to participate in. To reinforce the seriousness of the issues discussed, WPI students view a video ${ }^{18}$ produced specifically to cover these issues for students participating in study abroad.

While participants are off-campus they still have access through email, telephone, and fax to all support resources on the WPI campus. This specific contact information is provided in their handbooks. Students are also given laminated wallet cards with contact numbers (office, home and cellular) for the leadership team of the IGSD in case of an emergency. The WPI risk management team is confident that by providing written material to the students and their families along with a review of all the material, policies, and issues that all participants are as prepared as possible before they leave campus.

\section{The Return}

Re-entry programs for returning students from off-campus project centers have been offered for the past four years. Early pilot results showed the need for addressing some of the issues that students face as they return to campus life. A process of self-reflection and awareness is initiated and facilitated by members of the professional staff in the Global Perspective Program and the Counseling Center on campus. By being asked open-ended questions about their experiences, some students begin to come to terms with how they have been changed by their experience off campus. They are also given guidance as to how the experience could be used to inform their future academic and professional endeavors.

As students return to campus with a heightened sense of self-knowledge and awareness of their place in the world, along with an increased awareness of international issues never contemplated before, they are sometimes unable to articulate the depth of their experience. To help students, mock job interviews are conducted during re-entry to provide guidance about how best to talk about their experience off campus.

All returning students are encouraged to continue their experience by becoming active in the Global Ambassador program. This is a group of students who volunteer their time in efforts to

Proceedings of the 2001 American Society for Engineering Education Annual Conference \& Exposition Copyright 2001, American Society for Engineering Education 
communicate to others what going off campus means. Global Ambassadors give presentations to visiting VIPs to WPI, the Board of Trustees, prospective students and their families, as part of Family Weekend and to current WPI students. The result of the work done by the Global Ambassadors is evidenced in the sharp increase in participation in and awareness of the WPI Global Perspective Program.

\section{Summary}

The Global Perspective Program at WPI provides a model for international education that incorporates a meaningful global experience for engineering students. At WPI careful risk management, student selection, preparation and re-entry, and faculty development support these efforts. Rapid growth of the program provides evidence that WPI students understand the value of this type of international experience. The fact that with this increase of participation there have been no catastrophic incidents speaks to the success of the management of these experiences by those involved at WPI. Conscientious risk management is crucial to the success of any off campus academic experience, be it abroad or here in the United States.

Bibliography

1. Clinton, W. J., "Executive Memorandum on U.S. International Education Policy for the Heads of Executive Departments and Agencies," The White House, April 20, 2000.

2. "Engineering Education for a Changing World," A Joint Project by the Engineering Deans Council and the Corporate Round table of the American Society for Engineering Education, 1994.

3. Dewey, J., John Dewey on Education: Selected Writings. (R.D. Archambault, ed.). Chicago: University of Chicago Press, 1974.

4. Lave, J., and Wenger, E. (1991). Situated learning: Legitimate peripheral participation. New York:Cambridge University Press.

5. Hutchins, E., Cognition in the Wild, Cambridge, MA: MIT Press, 1995.

6. Dreyfus, H.L., and Dreyfus, S.E., Mind over Machine: The Power of Human Intuition and Expertise in the Era of the Computer, New York: Free Press, 1986.

7. Rogoff, B. (1990) Apprenticeship In Thinking: Cognitive Development In Social Context, New York: Oxford University Press.

8. Schön. D.A., Educating the Reflective Practitioner. San Francisco: Jossey-Bass, 1987.

9. Studying the Risks, The Detroit News Cyber Surveys, wysiwig://1/http://data.detnews.com/feedback/surveyletters.hbs

10. Rubin, K., Safety in Study Abroad: How much more can programs do to protect students? Promoting Safety in Study Abroad, NAFSA, 1998 http://www.nafsa.org/safetyabroad/rubin.html

11. Kast, R.C., In Loco Parentis and the "Reasonable Person", International Educator, Vol. VII, No. 1. NAFSA, 1997.

12. French, R. Gauging Danger a Difficult Task: Statistics NotKept; colleges have few rules, The Detroit News, 8/28/00 http://www.detnews.com/specialreport/costarica/mondanger/mondanger.html

13. SAFETI (Safety Abroad First - Educational Travel Information) Clearinghouse Project, On-Line Newsletter, University of Southern California Center for Global Education, 2001. http://www.usc.edu/dept/education/globaled/safeti/

14. Congressional Hearing Subject: Safety in Study Abroad Programs. Committee: Education and the Workforce. Subcommittee: Oversight and Investigations October 4, 2000.

15. Mello, N.A., How Can Universities Provide a Global Perspective for Engineers? One Institution's Solution, ASEE Annual Conference Proceedings, St. Louis, MO, June 2000.

Proceedings of the 2001 American Society for Engineering Education Annual Conference \& Exposition Copyright 2001, American Society for Engineering Education 
16. Vaz, R., Connected Learning: Interdisciplinary Projects in International Settings. Liberal Education, AAC\&U, Vol. 86, No. 1. Winter 2000.

17. NAFSA, Responsible Study Abroad: Health and Safety Guidelines, June 5, 1998 http://www.nafsa.org/safetyabroad/guidelines1298.html

18. Darrah, M., Safety and Study Abroad, Video Learning Program., Big World Inc., Boulder, CO., 1999

NATALIE A. MELLO

Natalie A. Mello is currently the Director of Global Operations in the Interdisciplinary and Global Studies Division at Worcester Polytechnic Institute. Her office oversees project centers in the following locations: London, England; San José, Costa Rica; Venice, Italy; Goddard Space Flight Center, MD; Silicon Valley, CA; Bangkok, Thailand; Washington, DC; Madrid, Spain; Zurich, Switzerland; San Juan, Puerto Rico; Copenhagen, Denmark; Boston, MA; and Melbourne, Australia. She earned her Bachelor of Arts from Connecticut College in 1984. In 1993, she received her MA from Clark University.

Proceedings of the 2001 American Society for Engineering Education Annual Conference \& Exposition Copyright 2001, American Society for Engineering Education 